University of Nebraska - Lincoln

DigitalCommons@University of Nebraska - Lincoln

2008

\title{
Trends in esophageal cancer incidence by histology, United States, 1998-2003
}

Katrina F. Trivers

Centers for Disease Control and Prevention, ktrivers@cdc.gov

Susan A. Sabatino

Centers for Disease Control and Prevention, SSabatino@cdc.gov

Sherri L. Stewart

Centers for Disease Control and Prevention, sstewart2@cdc.gov

Follow this and additional works at: https://digitalcommons.unl.edu/publichealthresources

Part of the Public Health Commons

Trivers, Katrina F.; Sabatino, Susan A.; and Stewart, Sherri L., "Trends in esophageal cancer incidence by histology, United States, 1998-2003" (2008). Public Health Resources. 271.

https://digitalcommons.unl.edu/publichealthresources/271

This Article is brought to you for free and open access by the Public Health Resources at DigitalCommons@University of Nebraska - Lincoln. It has been accepted for inclusion in Public Health Resources by an authorized administrator of DigitalCommons@University of Nebraska - Lincoln. 


\title{
Trends in esophageal cancer incidence by histology, United States, 1998-2003
}

\author{
Katrina F. Trivers*, Susan A. Sabatino and Sherri L. Stewart \\ Division of Cancer Prevention and Control, National Center for Chronic Disease Prevention and Health Promotion, \\ Centers for Disease Control and Prevention, Atlanta, GA
}

Esophageal adenocarcinoma rates may be increasing, whereas, squamous cell carcinoma rates appear to be decreasing in the United States. Previous population-based research on esophageal cancer has only covered up to $68 \%$ of the country. Additional, updated research on a larger percentage of the country is needed to describe racial, ethnic and regional trends in histologic subtypes of esophageal cancer. Invasive esophageal cancer cases diagnosed between 1998 and $2003(n=65,926)$, collected by the National Program of Cancer Registries or the Surveillance, Epidemiology, and End Results program, were included. These data cover $83 \%$ of the US population. Esophageal squamous cell carcinoma incidence fell by $3.6 \%$ /year, whereas esophageal adenocarcinoma increased by $2.1 \% / y e a r$. Squamous cell carcinoma rates decreased among both sexes in most racial or ethnic groups, whereas adenocarcinoma rates increased primarily among white or non-Hispanic men. Except for white or non-Hispanic men, squamous cell carcinoma rates were similar to, or greater than, adenocarcinoma rates for men and women of all other races and ethnicities. The largest decrease in squamous cell carcinoma rates occurred in the West census region, which also exhibited no increase in adenocarcinoma rates. The rate of regional and distant-staged adenocarcinomas increased, while rates for local-staged adenocarcinoma remained stable. This is the first article to characterize esophageal cancer trends using data covering the majority of the US. Substantial racial, ethnic and regional variation in esophageal cancer is present in the US. Our work may inform interventions related to tobacco and alcohol use, and overweight/obesity prevention, and provide avenues for further research.

Published 2008 Wiley-Liss, Inc. This article is a US Government work and, as such, is in the public domain in the United States of America.

Key words: esophageal neoplasms; epidemiology; United States

Little is known about the incidence of histologic subtypes of esophageal cancer at the national level. Esophageal cancer is relatively rare in the United States with 15,560 cases and 13,940 deaths expected to have occurred in 2007. ${ }^{1}$ However, rates of esophageal adenocarcinoma increased dramatically between the 1970s and 1990s, particularly among white men, with a reported rate of increase $(>350 \%)$ greater than for any other cancer. ${ }^{2,3}$ Racial and ethnic, ${ }^{2-11}$ and geographic ${ }^{12}$ differences in incidence have been observed, as well as differences by tumor stage. ${ }^{8,13}$ Nonetheless, few reports on esophageal cancer have included recent incidence and trend data ${ }^{2-13}$; no reports have published race- and sex-specific esophageal cancer trend estimates using data since 1998. Continued updates on esophageal cancer rates and trends at the national level are warranted given associations between esophageal adenocarcinoma and elevated body mass index ${ }^{14}$ and gastroesophageal reflux disease, ${ }^{15}$ both of which have increased over the past few decades. ${ }^{16,17}$ Furthermore, previous studies $^{2-13}$ have only captured up to $68 \%$ of the population with limited geographic diversity, limiting the ability to monitor national and regional trends in esophageal cancer incidence. In datasets with greater population coverage, such as the National Program of Cancer Registries (NPCR), evidence suggests that rates for tobacco-related cancers, including esophageal cancer, are higher than in the Surveillance, Epidemiology and End Results (SEER) program, ${ }^{18}$ possibly due to the inclusion of states with higher tobacco use in the former. Therefore, further research with such an expanded dataset covering a greater proportion of the US will allow for a more complete characterization of esophageal cancer incidence in the US, as was recently reported for Europe. ${ }^{19}$ The greater number of cases will also enable examination of rates and trends among smaller racial and ethnic groups, such as American Indian/Alaskan Natives (AI/AN) and Asian and Pacific Islanders (API) that have not been adequately studied.

The aim of our study was to fully characterize the incidence and trends of histologic subtypes of esophageal cancer by race, ethnicity, sex, geographic region and tumor characteristics (e.g., stage, grade) in the United States between 1998 and 2003. To date, this is the largest population-based nationwide study of esophageal cancer, based on data used to publish official national cancer statistics. Data in this analysis included $>65,000$ cases of esophageal cancer and covered $83 \%$ of the US population for these years. Whether rates of esophageal adenocarcinoma have continued to increase and what groups are disproportionately affected remain an important public health concern and may inform appropriate interventions.

\section{Material and Methods}

\section{Source population}

This report is comprised of data on newly diagnosed primary esophageal cancers from population-based statewide cancer registries participating in the Centers for Disease Control and Prevention's NPCR and/or the National Cancer Institute's SEER program. ${ }^{20,21}$ These are the 2 major sources of cancer surveillance data in the US and in combination are used to publish official national cancer statistics. Both sources use uniform methodologies for data collection and reporting. Only data from statewide registries that met strict high-quality standards ${ }^{22}$ for all years (1998-2003) are included in this report. High-quality standards for all cancer sites combined included $\geq 90 \%$ complete case ascertainment, $\leq 5 \%$ of cases ascertained solely based on death certificates, $\leq 3 \%$ of cases missing information on sex or age, $\leq 5 \%$ of cases missing information on race and $\geq 97 \%$ of registry's records passing a set of singleand inter-field edits. ${ }^{22}$ Included registries were from Alabama, Alaska, Arkansas, California, Colorado, Connecticut, Delaware, the District of Columbia, Florida, Hawaii, Idaho, Illinois, Indiana, Iowa, Kansas, Kentucky, Louisiana, Maine, Massachusetts, Michigan, Minnesota, Missouri, Montana, Nebraska, New Jersey, New Mexico, New York, Ohio, Oklahoma, Oregon, Pennsylvania, Rhode Island, South Carolina, Texas, Utah, Vermont, Washington, West Virginia and Wisconsin. All registries were established prior to 1997 and were required to submit data to CDC as of 1997; only incident cases were reportable and included. ${ }^{22}$ Data were continuously updated and monitored every year for quality and included all incident cases in a given state for the time period analyzed. ${ }^{22}$ Data from these registries covered $83 \%$ of the US population. Coverage

Abbreviations: AI/AN, American Indian or Alaskan Native; APC, annual percent change; API, Asian or Pacific Islander; CI, confidence interval; IR, incidence rate; NPCR, National Program of Cancer Registries; SEER, Surveillance Epidemiology and End Results Program.

Grant sponsors: Research Participation Program at the Centers for Disease Control and Prevention (CDC) [Oak Ridge Institute for Science and Education], Centers for Disease Control and Prevention's National Program of Cancer Registries.

*Correspondence to: Division of Cancer Prevention and Control, National Center for Chronic Disease Prevention and Health Promotion, Centers for Disease Control and Prevention, 4770 Buford Highway, NE, MS K-55, Atlanta, GA 30341, USA. Fax: +770-488-4639.

E-mail: ktrivers@cdc.gov

Received 17 January 2008; Accepted after revision 16 April 2008

DOI 10.1002/ijc.23691

Published online 10 June 2008 in Wiley InterScience (www.interscience. wiley.com) 
TABLE I - HISTOLOGIC SUBTYPES OF MICROSCOPICALLY CONFIRMED, INVASIVE ESOPHAGEAL CANCER, UNITED STATES, ${ }^{1}$ 1998-2003

\begin{tabular}{|c|c|c|}
\hline Histologic type & ICD-O-3 codes ${ }^{2}$ & Count $(\%)$ \\
\hline Squamous cell carcinoma & $8050-8082$ & $24,889(38 \%)$ \\
\hline Squamous cell carcinoma & 8070 & 22,366 \\
\hline Squamous cell carcinoma, keratinizing & 8071 & 1,928 \\
\hline $\begin{array}{l}\text { Squamous cell carcinoma, } \\
\text { large cell, nonkeratinizing }\end{array}$ & 8072 & 424 \\
\hline Squamous cell carcinoma, spindle cell & 8074 & 60 \\
\hline Other & & 111 \\
\hline Adenocarcinoma & $8140-8573$ & $36,800(56 \%)$ \\
\hline Adenocarcinoma, NOS & 8140 & 32,746 \\
\hline Adenocarcinoma, intestinal type & 8144 & 217 \\
\hline Neuroendocrine carcinoma, NOS & 8246 & 119 \\
\hline Adenocarcinoma with mixed subtypes & 8255 & 51 \\
\hline Papillary adenocarcinoma & 8260 & 194 \\
\hline $\begin{array}{l}\text { Mucinous adenocarcinoma and } \\
\text { mucin-producing adenocarcinoma }\end{array}$ & $8480-8481$ & 1,306 \\
\hline Signet ring cell carcinoma & 8490 & 1,416 \\
\hline Adenosquamous carcinoma & 8560 & 551 \\
\hline Other & & 200 \\
\hline All others & $\begin{array}{c}8000-8046,8083-8084, \\
8090-8130,8574-8576,8580-9581\end{array}$ & $4,237(6 \%)$ \\
\hline Cancer, NOS & 8000 & 428 \\
\hline Carcinoma, NOS & 8010 & 2,606 \\
\hline Large cell carcinoma & 8012 & 174 \\
\hline Carcinoma, undifferentiated, NOS & 8020 & 114 \\
\hline Small cell carcinoma & $8041-8045$ & 364 \\
\hline Nonsmall cell carcinoma & 8046 & 98 \\
\hline Basaloid squamous cell carcinoma & 8083 & 87 \\
\hline Malignant melanomas & $8720,8742,8772$ & 57 \\
\hline Leiomyosarcomas & $8890,8891,8895$ & 38 \\
\hline Other & & 271 \\
\hline Total & & 65,926 \\
\hline
\end{tabular}

NOS, not otherwise specified.

${ }^{1}$ Data from registries meeting quality standards for all years, representing $83 \%$ of the U.S. population.- ${ }^{2}$ Codes from International Classification of Diseases for Oncology, 2nd edition, (ICD-O-2) were used for patients diagnosed between 1998 and 2000 and subsequently converted to International Classification of Diseases for Oncology, 3rd edition (ICD-O-3) codes. ICD-O-3 codes were used for patients diagnosed for $2001+$.

varied by region, with data from the Northeast and Midwest covering approximately $98 \%$ of their respective populations, and from the West and South covering 88 and $63 \%$, respectively. There were 69,766 cases of invasive, primary esophageal cancer reported from the previously listed registries, excluding lymphomas arising in the esophagus. Microscopic confirmation was not available for 3,840 cases and these were excluded from all analyses, leaving 65,926 cases for use in our study.

Similar to procedures in previous studies ${ }^{2,3,12}$ esophageal cancers were categorized into the following histologies: squamous cell carcinoma, adenocarcinoma and all others. Esophageal cancers were grouped using the morphology codes from the International Classification of Diseases for Oncology, Third Edition (ICD-O-3). ${ }^{23}$ The codes for each group, as well as selected subgroups, are listed in Table I. Morphology codes for cases diagnosed between 1998 and 2000 were coded using the ICD-O, Second Edition ${ }^{24}$ and subsequently converted to ICD-O-3 codes. ${ }^{25}$ No morphology codes for esophageal cancer differed between the second and third editions. ${ }^{23}$ Tumor stage was defined as SEER Summary Stage (local, confined to the esophagus; regional, invaded adjacent tissues or spread to regional lymph nodes; or distant, metastasized or with distant lymph node involvement). ${ }^{26}$ Starting with 2001 diagnoses, Summary Stage 2000 criteria were used ${ }^{26}$ and earlier diagnoses used Summary Stage 1977 rules. ${ }^{27}$ The differences between the 2 staging systems were minimal for esophageal cancer. ${ }^{28}$

Race was directly coded from the medical record and categorized as white, black, Asian or Pacific Islander (API), AI/AN or unknown. To minimize the effects of racial misclassification of AI/AN, the Indian Health Service (IHS) patient registration database was used to link cancer registry data on a routine basis. ${ }^{29,30}$
IHS provides medical services to AI/AN who are members of federally recognized tribes only, which is estimated to be approximately $57 \%$ of the AI/AN population in the US. ${ }^{30} \mathrm{Up}$ to $26 \%$ of individuals that were not identified as $\mathrm{AI} / \mathrm{AN}$ in the registry linked to the IHS patient registration database and were reclassified as $\mathrm{AI} / \mathrm{AN}$ as a result of the linkage (personal communication, Melissa A. Jim, IHS). Ethnicity was categorized as Hispanic or nonHispanic. Ethnicity information was augmented by the North American Association of Central Cancer Registries Hispanic Identification Algorithm (NHIA), which utilizes birthplace, race and/or surname information. ${ }^{31,32}$ Up to $36 \%$ of people were reclassified from unknown to known ethnicity due to NHIA in an analysis of registry data from 1997 to $2001 .^{33}$ Race and ethnicity are not mutually exclusive and categories are consistent with federal guidelines for reporting race and ethnicity. ${ }^{22}$

\section{Statistical analyses}

Number of cases and age-adjusted incidence rates, along with 95\% confidence intervals (CIs), are presented for the different histologic subtypes of esophageal cancer. Trends in incidence rates over time were analyzed by examining annual percentage change (APC) with 95\% CIs over the 6-year period. Statistically significant $(p<0.05)$ APCs are highlighted throughout the text. However, nonsignificant results are also discussed when the results appeared to be clinically meaningful. Rates are per 100,000 persons and are age-adjusted to the 2000 US standard population in 5 -year age groups. Results were suppressed for groups that included $<6$ people to protect confidentiality as well as prevent presentation of unstable estimates. APCs were suppressed if $<6$ cases were present in one or more years. ${ }^{34}$ SEER*Stat software version 6.2.4 $4^{35}$ was used. 
TABLE II - DISTRIBUTION OF DEMOGRAPHIC, GEOGRAPHIC AND TUMOR CHARACTERISTICS BY HISTOLOGIC SUBTYPES OF MICROSCOPICALLY CONFIRMED, INVASIVE ESOPHAGEAL CANCER, UNITED STATES, ${ }^{1} 1998-2003$

\begin{tabular}{|c|c|c|c|}
\hline & Squamous cell carcinoma $n(\%)$ & Adenocarcinoma $n(\%)$ & All others $n(\%)$ \\
\hline \multicolumn{4}{|l|}{ Age, years } \\
\hline$<45$ & $551(2.2)$ & $1,353(3.7)$ & $129(3.0)$ \\
\hline $45-59$ & $5,353(21.5)$ & $8,947(24.3)$ & $815(19.2)$ \\
\hline $60-74$ & $11,248(45.2)$ & $15,687(42.6)$ & $1,780(42.0)$ \\
\hline $75+$ & $7,737(31.1)$ & $10,813(29.4)$ & $1,513(35.7)$ \\
\hline \multicolumn{4}{|l|}{ Region $^{1}$} \\
\hline Northeast & $6,728(27.0)$ & $9,445(25.7)$ & $971(22.9)$ \\
\hline Midwest & $6,409(25.8)$ & $11,561(31.4)$ & $1,150(27.1)$ \\
\hline South & $7,251(29.1)$ & $8,696(23.6)$ & $1,315(31.0)$ \\
\hline West & 4,501 (18.1) & 7,098 (19.3) & $801(18.9)$ \\
\hline \multicolumn{4}{|l|}{ Summary stage } \\
\hline Local & $6,140(31.4)$ & $8,964(29.1)$ & $708(25.5)$ \\
\hline Regional & 7,735 (39.5) & $10,730(34.9)$ & $694(25.0)$ \\
\hline Distant & $5,710(29.2)$ & $11,093(36.0)$ & $1,377(49.6)$ \\
\hline \multicolumn{4}{|l|}{ Grade } \\
\hline Well (I) & $1,339(6.6)$ & $2,110(6.8)$ & $28(1.2)$ \\
\hline Moderate (II) & $9,668(47.3)$ & $11,974(38.7)$ & $79(3.3)$ \\
\hline Poorly (III) & $9,166(44.9)$ & $16,274(52.5)$ & $1,746(73.0)$ \\
\hline Undifferentiated (IV) & $254(1.2)$ & $615(2.0)$ & $539(22.5)$ \\
\hline \multicolumn{4}{|l|}{ Ethnicity $^{2}$} \\
\hline Non-Hispanic & $23,423(94.1)$ & $35,571(96.7)$ & 3,997 (94.3) \\
\hline Hispanic & $1,466(5.9)$ & $1,229(3.3)$ & $240(5.7)$ \\
\hline \multicolumn{4}{|l|}{$\operatorname{Race}^{2^{\mathrm{x}}}$} \\
\hline White & $17,351(70.1)$ & $35,313(96.7)$ & $3,636(86.4)$ \\
\hline Black & $6,475(26.2)$ & $891(2.4)$ & $495(11.8)$ \\
\hline AI/AN & $101(0.4)$ & $123(0.3)$ & $17(0.4)$ \\
\hline API & $816(3.3)$ & $200(0.5)$ & $62(1.5)$ \\
\hline \multicolumn{4}{|l|}{ Sex } \\
\hline Men & $16,097(64.7)$ & $31,116(84.6)$ & $3,042(71.8)$ \\
\hline Women & $8,792(35.3)$ & $5,684(15.5)$ & $1,195(28.2)$ \\
\hline
\end{tabular}

AI/AN, American Indian/Alaska Native; API, Asian or Pacific Islander; NPCR, National Program of Cancer Registries; SEER, Surveillance, Epidemiology and End Results Program.

${ }^{1}$ Data from registries meeting quality standards for all years, representing $83 \%$ of the U.S. population (population coverage by region: Northeast, $98 \%$; Midwest, $98 \%$; West, $88 \%$; South, $63 \%$ ).- ${ }^{2}$ Race and ethnicity are not mutually exclusive.

\section{Results}

The majority of esophageal cancers $(56 \%)$ diagnosed between 1998 and 2003 were adenocarcinomas, most of which were not further specified (Table I). The next largest groups of specified adenocarcinoma subtypes included mucinous adenocarcinoma or mucin-producing adenocarcinoma $(3.5 \%)$ and signet ring cell carcinoma $(3.8 \%)$. Tumors that could not be classified as either adenocarcinoma or squamous cell carcinoma ("all other histologies," $6 \%$ ) were typically unspecified histologies (e.g. cancer, NOS; carcinoma, NOS).

Among those diagnosed with squamous cell carcinomas, $70 \%$ were white, $26 \%$ were black and $3 \%$ were API (Table II). Adenocarcinomas were more frequently diagnosed among whites $(97 \%)$. About $65 \%$ of squamous cell carcinomas but $85 \%$ of adenocarcinomas were diagnosed among men. Adenocarcinomas were also more likely to be diagnosed at distant stage $(36 \%)$ and grades III/ IV $(55 \%)$ than squamous cell carcinomas (29 and 46\%, respectively). The only variables with substantial missing data were stage and grade (data not shown). Among squamous cell carcinoma cases, 21.3 and $17.9 \%$ were missing stage and grade information, respectively. The same percentages among adenocarcinomas were 16.3 and $15.8 \%$.

Between 1998 and 2003, the overall age-adjusted rates of squamous cell carcinoma and adenocarcinoma of the esophagus were 1.8 per $100,000(95 \% \mathrm{CI}=1.7,1.8)$ and 2.6 per $100,000(95 \% \mathrm{CI}$ $=2.6,2.6$ ), respectively (Table III). The rate of squamous cell carcinoma fell by an average of $3.6 \%$ per year whereas rates of adenocarcinoma of the esophagus rose by $2.1 \%$ per year. When examining subtypes of adenocarcinomas, mucinous or mucin-producing adenocarcinoma rates did not increase (data not shown), but signet ring adenocarcinoma rates did increase $(\mathrm{APC}=8.9 \%$, $95 \% \mathrm{CI}=1.0,17.4)$.
Rates of both squamous cell carcinoma and adenocarcinoma increased with age, particularly after 60 years of age (Table III). The highest rates of squamous cell carcinoma were in the Northeast, and adenocarcinoma rates were highest in the Midwest. Western states exhibited both the greatest decrease in squamous cell carcinoma rates and no increase in adenocarcinoma rates. The lack of increase in adenocarcinoma in the Western region appeared to be driven by decreases of 2.1 and $8.3 \%$ in 2 states. Results for the entire sample were unchanged when these 2 states were excluded.

Increases in rates of adenocarcinomas with poor prognostic factors, including those with distant stage and poorly differentiated grade, occurred between 1998 and 2003 whereas rates of local and well-differentiated disease were stable over this period. Distantstage adenocarcinomas also tended to have poorly differentiated grade, and occurred more frequently among black men and women, younger men and women, and men (data not shown). For both histologies, the percentage of patients with unknown stage decreased over time (data not shown). Among adenocarcinomas, 18.5 and $14.8 \%$ had unknown stage in 1998 and 2003, respectively; for squamous cell carcinoma, the corresponding percentages were 23.3 and $19.8 \%$.

Adenocarcinoma rates were higher for non-Hispanics than Hispanics $(\mathrm{IR}=2.7 ; 95 \% \mathrm{CI}=2.7,2.7$ and $\mathrm{IR}=1.3 ; 95 \% \mathrm{CI}=1.2$, 1.4 , respectively). Rates of adenocarcinoma did not increase among Hispanics during the 6-year study period, although rates for non-Hispanics did increase (APC $=2.3 ; 95 \% \mathrm{CI}=1.3,2.4$ ). Among racial groups, the highest rate of adenocarcinoma was among whites $(\mathrm{IR}=2.8 ; 95 \% \mathrm{CI}=2.8,2.9)$, followed by $\mathrm{AI} / \mathrm{AN}$ $(\mathrm{IR}=1.6 ; 95 \% \mathrm{CI}=1.3,1.9)$. API had the lowest rate of adenocarcinoma $(\mathrm{IR}=0.4 ; 95 \% \mathrm{CI}=0.4,0.5)$. In all racial groups, adenocarcinoma rates appeared to increase over time; however, for groups other than white persons $(\mathrm{APC}=2.2 ; 95 \% \mathrm{CI}=1.0,3.4)$, CIs were wide and included zero. Rates of squamous cell carci- 
TABLE III - AGE-ADJUSTED INCIDENCE RATES AND TRENDS OVER TIME OF HISTOLOGIC SUBTYPES OF MICROSCOPICALLY CONFIRMED, INVASIVE ESOPHAGEAL CANCER, BY DEMOGRAPHIC, GEOGRAPHIC AND TUMOR CHARACTERISTICS, UNITED STATES, ${ }^{1} 1998-2003$

\begin{tabular}{|c|c|c|c|c|}
\hline & \multicolumn{2}{|c|}{ Squamous cell carcinoma } & \multicolumn{2}{|c|}{ Adenocarcinoma } \\
\hline & $\mathrm{IR}^{2}(95 \% \mathrm{CI})$ & $\operatorname{APC}^{3}(95 \% \mathrm{CI})$ & $\mathrm{IR}^{2}(95 \% \mathrm{CI})$ & $\mathrm{APC}^{3}(95 \% \mathrm{CI})$ \\
\hline Overall & $1.8(1.7,1.8)$ & $-3.6^{*}(-4.6,-2.5)$ & $2.6(2.6,2.6)$ & $2.1 *(1.0,3.3)$ \\
\hline \multicolumn{5}{|l|}{ Age, years } \\
\hline$<45$ & $0.1(0.1,0.1)$ & $-3.4(-8.7,2.3)$ & $0.2(0.1,0.2)$ & $2.7(-2.4,8.0)$ \\
\hline $45-59$ & $2.0(2.0,2.1)$ & $-3.7 *(-5.4,-1.9)$ & $3.4(3.4,3.5)$ & $1.8(-0.4,4.0)$ \\
\hline $60-74$ & $7.6(7.5,7.8)$ & $-4.1 *(-5.5,-2.7)$ & $10.7(10.5,10.8)$ & $1.9 *(0.2,3.6)$ \\
\hline $75+$ & $9.0(8.8,9.2)$ & $-2.6 *(-3.9,-1.3)$ & $12.6(12.4,12.8)$ & $2.7 *(1.1,4.3)$ \\
\hline \multicolumn{5}{|l|}{ Region $^{1}$} \\
\hline Northeast & $2.0(1.9,2.0)$ & $-3.0 *(-4.2,-1.9)$ & $2.8(2.7,2.9)$ & $3.5 *(2.2,4.9)$ \\
\hline Midwest & $1.7(1.6,1.7)$ & $-2.6 *(-5.8,0.7)$ & $3.0(3,3.1)$ & $1.9(0.0,3.8)$ \\
\hline South & $1.9(1.8,1.9)$ & $-3.8 *(-5.6,-1.9)$ & $2.2(2.2,2.3)$ & $2.7 *(0.6,4.8)$ \\
\hline West & $1.5(1.5,1.6)$ & $-5.3 *(-7.4,-3.1)$ & $2.4(2.3,2.4)$ & $0.4(-2.8,3.6)$ \\
\hline \multicolumn{5}{|l|}{ Summary stage } \\
\hline Local & $0.4(0.4,0.4)$ & $-6.9^{*}(-10.5,-3.2)$ & $0.6(0.6,0.6)$ & $1.1(-1.7,4.0)$ \\
\hline Regional & $0.5(0.5,0.6)$ & $-1.8^{*}(-2.5,-1.0)$ & $0.8(0.7,0.8)$ & $3.3 *(0.4,6.2)$ \\
\hline Distant & $0.4(0.4,0.4)$ & $0.1(-2.6,2.9)$ & $0.8(0.8,0.8)$ & $4.3 *(3.1,5.5)$ \\
\hline \multicolumn{5}{|l|}{ Grade } \\
\hline Well (I) & $0.1(0.1,0.1)$ & $-5.5 *(-7.7,-3.1)$ & $0.1(0.1,0.2)$ & $-0.9(-2.6,0.9)$ \\
\hline Moderate (II) & $0.7(0.7,0.7)$ & $-3.4 *(-4.6,-2.1)$ & $0.8(0.8,0.9)$ & $1.5 *(0.6,2.4)$ \\
\hline Poorly (III) & $0.6(0.6,0.7)$ & $-3.8 *(-4.7,-3.0)$ & $1.2(1.1,1.2)$ & $2.2 *(0.4,4.1)$ \\
\hline Undifferentiated (IV) & $0(0,0)$ & $-10.4(-23.2,4.5)$ & $0(0,0)$ & $-0.1(-6.5,6.7)$ \\
\hline
\end{tabular}

AI/AN, American Indian/Alaska Native; API, Asian or Pacific Islander; CI, confidence interval.

${ }^{1}$ Data from registries meeting quality standards for all years, representing $83 \%$ of the U.S. population (population coverage by region: Northeast, 98\%; Midwest, 98\%; West, 88\%; South, 63\%).- ${ }^{2}$ IR, incidence rate (per 100,000 and age-adjusted to the 2000 US Standard Population). ${ }^{3}$ APC, annual percent change between 1998 and $2003 .-*$ APC is statistically significantly $(p<0.05)$ different than zero.

TABLE IV - INCIDENCE RATES AND TRENDS OVER TIME OF MICROSCOPICALLY CONFIRMED, INVASIVE, SQUAMOUS CELL CARCINOMA AND ADENO-

\begin{tabular}{|c|c|c|c|c|c|c|}
\hline & \multicolumn{3}{|c|}{ Squamous cell } & \multicolumn{3}{|c|}{ Adenocarcinoma } \\
\hline & $n(\%)$ & $\mathrm{IR}^{2}(95 \% \mathrm{CI})$ & $\mathrm{APC}^{3}(95 \% \mathrm{CI})$ & $n(\%)$ & $\mathrm{IR}^{2}(95 \% \mathrm{CI})$ & $\mathrm{APC}^{3}(95 \% \mathrm{CI})$ \\
\hline \multicolumn{7}{|l|}{$\operatorname{Men}^{4}$} \\
\hline White & $10,749(43.4)$ & $2(1.9,2.0)$ & $-3.4 *(-4.7,-2.1)$ & $29,967(82.0)$ & $5.4(5.4,5.5)$ & $2.1 *(1.0,3.2)$ \\
\hline Black & $4,579(18.5)$ & $9.3(9.0,9.6)$ & $-5.2 *(-7.3,-3.2)$ & $662(1.8)$ & $1.4(1.3,1.5)$ & $0.4(-6.3,7.5)$ \\
\hline $\mathrm{AI} / \mathrm{AN}$ & $79(0.3)$ & $2.5(1.9,3.2)$ & $-7.3(-27.4,18.4)$ & $102(0.3)$ & $3.0(2.4,3.7)$ & $12.0(-9.7,38.9)$ \\
\hline API & $602(2.4)$ & $3.0(2.7,3.2)$ & $-10.4 *(-15.1,-5.4)$ & $158(0.4)$ & $0.8(0.7,0.9)$ & $4.9(-9.9,22.1)$ \\
\hline \multicolumn{7}{|l|}{ Women $^{4}$} \\
\hline White & $6,602(26.7)$ & $0.9(0.9,0.9)$ & $-3.0 *(-5.2,-0.7)$ & $5,346(14.6)$ & $0.8(0.7,0.8)$ & $1.6(-1.0,4.3)$ \\
\hline Black & $1,896(7.7)$ & $2.8(2.7,2.9)$ & $-2.3(-5.3,0.8)$ & $229(0.6)$ & $0.3(0.3,0.4)$ & $9.3(-1.2,20.9)$ \\
\hline $\mathrm{AI} / \mathrm{AN}$ & $22(0.1)$ & $0.5(0.3,0.8)$ & $\sim$ & $21(0.1)$ & $0.5(0.3,0.8)$ & $\sim$ \\
\hline API & $214(0.9)$ & $0.9(0.7,1)$ & $-6.7(-18.1,6.3)$ & $42(0.1)$ & $0.2(0.1,0.2)$ & $\sim$ \\
\hline \multicolumn{7}{|l|}{$\mathrm{Men}^{4}$} \\
\hline Non-Hispanic & $15,036(60.4)$ & $2.6(2.6,2.6)$ & $-3.9 *(-4.5,-3.3)$ & $30,113(81.8)$ & $5.2(5.1,5.3)$ & $2.2 *(1.2,3.2)$ \\
\hline Hispanic & $1,061(4.3)$ & $2.6(2.4,2.8)$ & $-6.5^{*}(-8.8,-4.2)$ & $1,003(2.7)$ & $2.4(2.2,2.6)$ & $1.2(-3.0,5.4)$ \\
\hline \multicolumn{7}{|l|}{ Women $^{4}$} \\
\hline Non-Hispanic & $8,387(33.7)$ & $1.1(1.1,1.1)$ & $-2.7 *(-4.9,-0.4)$ & $5,458(14.8)$ & $0.7(0.7,0.7)$ & $2.1(-0.1,4.2)$ \\
\hline Hispanic & $405(1.6)$ & $0.8(0.7,0.9)$ & $-3.3(-10.7,4.7)$ & $226(0.6)$ & $0.5(0.4,0.5)$ & $-6(-16.9,6.2)$ \\
\hline
\end{tabular}

AI/AN, American Indian/Alaska Native; API, Asian or Pacific Islander; CI, confidence interval.

${ }^{1}$ Data from registries meeting quality standards for all years, representing $83 \%$ of the U.S. population. $-{ }^{2}$ IR, incidence rate (per 100,000 and age-adjusted to the 2000 US Standard Population). $-{ }^{3}$ APC, annual percent change between 1998 and $2003 .-{ }^{4}$ Race and ethnicity are not mutually exclusive. $-\sim$ Statistic could not be calculated $(<6$ cases in $\geq 1$ year).-*APC is statistically significantly $(p<0.05)$ different than zero.

noma were highest in blacks ( $\mathrm{IR}=5.5 ; 95 \% \mathrm{CI}=5.3,5.6)$ and similar in all other racial groups (IR between 1.3 and 1.8). Squamous cell carcinoma rates decreased over time for all racial groups, although the decrease was not statistically significant for AI/AN. Compared to women, men had approximately 2.4 times the rate of squamous cell carcinoma (IR for men $=2.6 ; 95 \% \mathrm{CI}=$ $2.5,2.6$ ) and over 7 times the rate of adenocarcinoma (IR for men $=5.0 ; 95 \% \mathrm{CI}=4.9,5.1$ ).

Substantial differences in incidence of histologic subtypes of esophageal cancer were present for combinations of race, ethnicity and sex (Table IV). Among black men and women, API men and women and non-Hispanic and Hispanic women, the incidence of squamous cell carcinoma was higher than that of adenocarcinoma. Among black men and women, squamous cell carcinoma incidence exceeded adenocarcinoma incidence by 6.6 and 9.3 times, respectively. Squamous cell carcinoma and adenocarcinoma inci- dence were similar among AI/AN men and women, white women and Hispanic men. Adenocarcinoma incidence was greater than squamous cell incidence only for white men and non-Hispanic men. Squamous cell carcinoma rates decreased for all race, ethnicity and sex combinations, although APCs were nonsignificant in some groups (Table IV, Figs. 1 and 2). Except for black men and Hispanic women, APC estimates for all race, ethnicity and sex combinations exceeded 1.0 for adenocarcinoma, although CIs were wide and many included zero (Table IV, Figs. 3 and 4).

\section{Discussion}

Using more recent nation-wide data from population-based cancer registries with substantially increased population coverage compared to previous studies, we found that most groups defined by race, ethnicity, sex and region showed increasing rates of adenocar- 


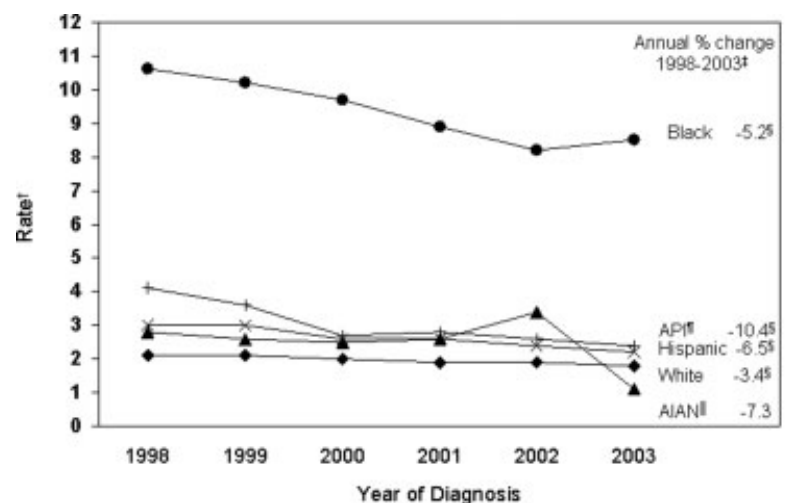

Data are from selected state and metropofitan area cancer registries that meet data quality crteria for all invasive cancet Stes for al years (1986-2003).

Morsoma and are age adustad to the 2000 U S. standard population.

an herease in rese.

Avenual percent change is statistically signícantly $(\rho<0.05)$ different than zero

Asian or Pacifc lesiander.

Figure 1 - Age-adjusted annual invasive esophageal squamous cell carcinoma rates in males, by race and ethnicity, US*, 1998-2003.

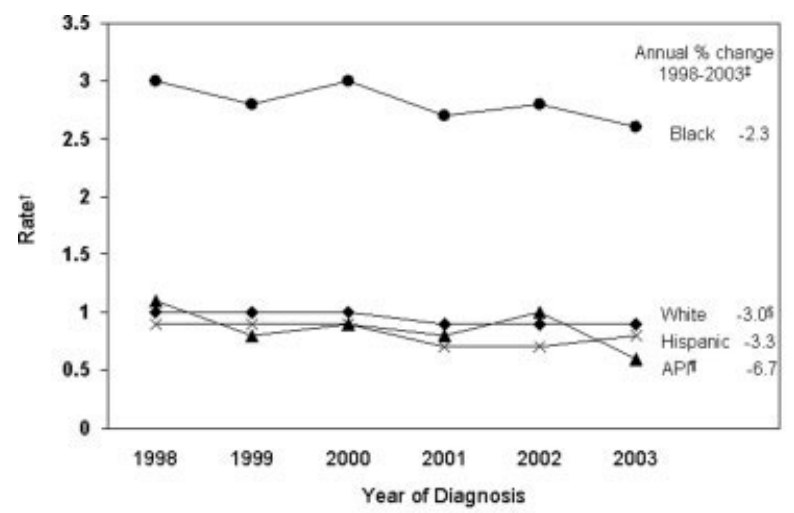

"Data are from selected state and motropoltan area cancer registries that meet data qualty criteria for at imrasime cancer sites for all years (1998-2003)

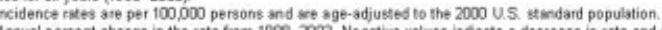
an increase in rate.

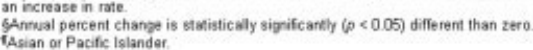

Estimates could not be calculated for American lofians of Alsska Naxives.

Figure 2 - Age-adjusted annual invasive esophageal squamous cell carcinoma rates in females, by race and ethnicity, US*, 1998-2003.

cinoma and decreasing rates of squamous cell carcinoma over time. Previous studies have observed that squamous cell carcinoma rates have declined or remained stable for studied racial and ethnic groups. $^{7-9}$ Our findings add that for many groups, squamous cell carcinoma rates were continuing to fall as of 2003. Despite decreases in squamous cell carcinoma incidence, many groups classified by sex, race and ethnicity exhibited higher rates of squamous cell carcinoma than adenocarcinoma. This burden of squamous cell carcinoma for many racial and ethnic groups underscores the need for continued awareness and education about squamous cell carcinoma, as well as interventions to reduce risk for developing disease.

The current study also provides updated national estimates of incidence and trends for smaller, less studied subgroups such as $\mathrm{AI} / \mathrm{AN}$ and API, including sex-specific rates. AI/AN had the second highest adenocarcinoma incidence of any racial group, whereas API had the lowest adenocarcinoma incidence. Consistent with our results among AI/AN persons, an earlier study of Alaska Natives noted a high incidence of esophageal cancer (all histologies combined) compared to other races. ${ }^{36}$ Ours is the first study to provide stable and reliable sex- and histology-specific rate and trend estimates for the AI/AN population. Previous literature

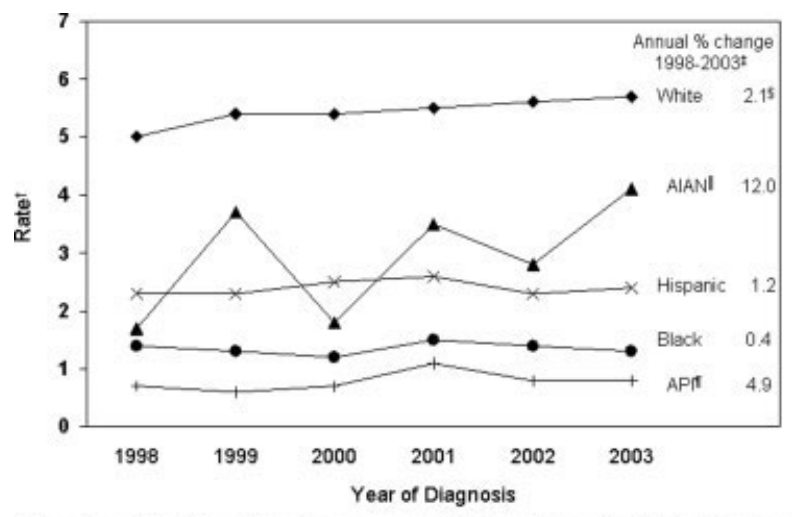

"Dats are frem seiected state and metropoltan ares cancer registries that meet data quality criteria for al inrasive cancer sites for all years (1998-2003).

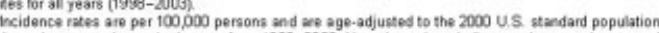

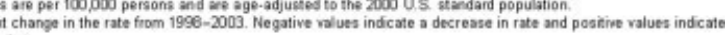
an increase in rale Asian of Pacfic Islander. Ammerican hdian/Alaska Native.

Figure 3 - Age-adjusted annual invasive esophageal adenocarcinoma rates in males, by race and ethnicity, US*, 1998-2003.

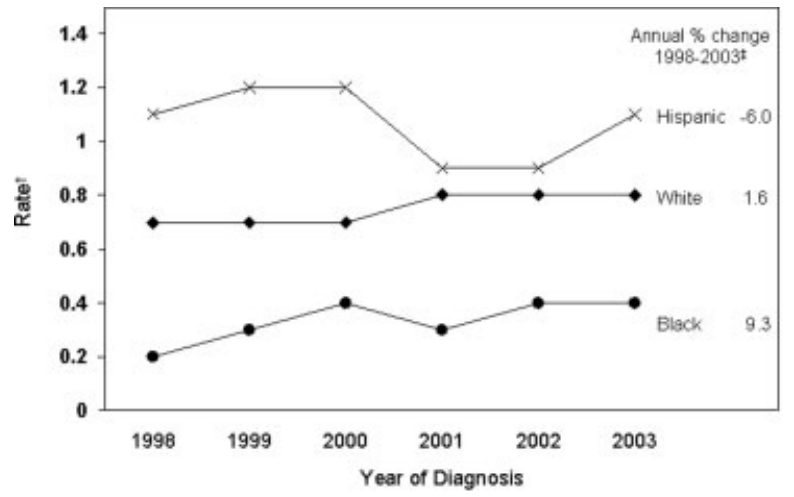

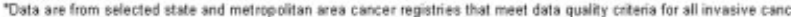
sitas for all years (195e-2003) tincidence rates are per 100,000 persons and are age-ajusted to the 2000 U.S. atandard population.

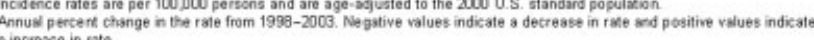

Estimales could not be calculsed for Asim or Pacife Islanders or American Indians or Alaska Natives.

Figure 4 - Age-adjusted annual invasive esophageal adenocarcinoma rates in females, by race and ethnicyt, US*, 1998-2003.

among $\mathrm{API}^{10}$ and Asian Americans ${ }^{7}$ observed that squamous cell carcinoma incidence was greater than adenocarcinoma incidence, similar to our results.

Contrary to previous literature that indicated increases in adenocarcinoma for Hispanic men and women, ${ }^{8}$ our data suggest that rates of adenocarcinoma did not increase for Hispanic women, and may have only minimally increased for Hispanic men.

We did not observe a large increase in adenocarcinoma among black men, as has been previously reported ${ }^{2-4,6,7}$; however, our shorter time frame might have limited our ability to detect time trends for some subgroups of adenocarcinoma patients. Additionally, differences among studies may have occurred in part due to temporal variation. Previous studies have observed a high incidence of squamous cell carcinoma among black men. ${ }^{7-9,1}$

In the present study, Western residents had the largest decrease in squamous cell carcinoma rates and no increase in adenocarcinoma rates. This is the first study to examine incidence and trends in esophageal cancer by census regions of the US, rather than relying on examination of noncontiguous registries. Geographic differences in esophageal cancer incidence have been previously reported,${ }^{12}$ but previous literature has been limited by examination of disparate areas, making inter-regional comparisons in previous 
studies difficult. Further research is needed to identify reasons for regional differences.

Importantly, the rate of regional and distant-stage adenocarcinoma increased more rapidly than that of local-stage tumors, and, for both histologies, rates of unstaged disease decreased. These results are consistent with findings from a previous study of the 1988-1993 National Cancer Data Base. ${ }^{13}$ However, a study of SEER data from 1973 through 1998 observed that the incidence of Stage IV disease decreased. ${ }^{8}$ It is unclear whether the observed increase in distant-stage adenocarcinoma in our data is real or if it reflects more accurate staging over time; it is possible cases that historically were classified as unstaged are now being correctly classified as distant.

Our results indicate a smaller magnitude of increase of esophageal adenocarcinoma ( $2.1 \%$ among white men) than previously reported. ${ }^{2-5,7,8}$ Previous studies estimated that, between 1976 and 1987, the average annual rates of increase in adenocarcinoma were $9.4 \%$ for white men, $9.8 \%$ for black men and $4.5 \%$ for white women. ${ }^{2}$ Based on publicly available data from population-based registries covering $9.5 \%$ of the country, ${ }^{37}$ the APC of invasive, microscopically confirmed esophageal adenocarcinoma for white men between 1985 and 1998 was $6.8 \%$ (95\% CI = 5.8, 7.9). These findings combined with our results may suggest an ongoing deceleration in adenocarcinoma rates. However, differences in populations covered by various data sources must be considered.

Modifiable risk factors for esophageal cancer may be amenable to population-based interventions. Squamous cell carcinoma of the esophagus is associated with tobacco use and alcohol consumption, ${ }^{14,38}$ and these factors and low consumption of fruits and vegetables may account for $89 \%$ of cases. ${ }^{39}$ Adenocarcinoma is associated with tobacco use, gastroesophageal reflux disease and elevated body mass index ${ }^{14,38}$ and approximately $79 \%$ of cases may be attributed to these factors, or low consumption of fruits and vegetables. ${ }^{39}$ Recent decreases in cigarette use, particularly among men, ${ }^{40}$ have likely contributed to the decrease in squamous cell carcinoma. However, esophageal adenocarcinoma risk remains elevated after tobacco cessation, ${ }^{38}$ suggesting that decreases in smoking-associated adenocarcinoma may take longer to be observed. The prevalence of overweight increased from 56 to $65 \%$ between the periods 1988-1994 and 1999-2000, and obesity prevalence increased from 8 to $13 \%$ during the same time frame. ${ }^{17}$ These increases may have contributed to the increase in esophageal adenocarcinoma. Multiple strategies to decrease tobacco use and prevent overweight and obesity have been found to be effective and summarized by the Guide to Community Preventive Services, which reviews and recommends community and health care system interventions (www.thecommunityguide.org). ${ }^{41,42}$ Combining surveillance research with effective community interventions may help reduce the burden of tobacco- and obesity-associated cancers.

Limitations to our study may have influenced our results. No risk factor information was available, so we were unable to examine the influence of risk factors such as tobacco and alcohol use, and obesity on incidence trends. Even in this large dataset, some groups of interest had small sample sizes. Also, the short time frame may have limited our power to examine trends over time. Data were largely based on medical records, thus some misclassification is possible, particularly for race and ethnicity. While data for whites and blacks are typically reliable, cancer cases for $\mathrm{AI} /$ AN, API and Hispanics may be underestimated, ${ }^{43,44}$ although the IHS linkages and Hispanic identification algorithm likely reduced such misclassification. In the South, the population covered by the data in this report $(63 \%)$ was lower than in other regions, and the population not covered by the data may differ from the included population. Reliable information is not available to adequately compare included and excluded states for characteristics such as socioeconomic status and race/ethnicity. Therefore, the magnitude and direction of potential bias from missing data is unknown. Despite this limitation, our study included the largest population coverage to date. Furthermore, there was no centralized pathology review. However, although some variation exists among individual pathologists, data quality studies have shown that histology data in NPCR registries are $91 \%$ accurate. ${ }^{45}$ The percentage of unspecified histology diagnoses, sometimes a measure of data quality in registries, was very low (on average, $<5 \%$ ). Furthermore, percentages of individual esophageal histologies (adenocarcinoma and squamous cell carcinoma) and of unknown stage and grade were reported similarly across the majority of registries, including those from NPCR registries and those funded only by SEER. Last, high quality data standards pertain to all cancer cases combined and may not specifically apply to esophageal cancers. However, quality criteria are not likely to vary much by cancer site. ${ }^{45}$

This is the largest population-based study in the US to examine incidence and trends in histologic subtypes of esophageal cancer, and we were able to expand previous knowledge about ethnic, racial and regional differences in esophageal cancer incidence. The large sample size allowed estimation of sex-specific rates for previously understudied groups such as AI/AN and API, as well as comparisons by geographic region. The wide population coverage of the data allowed for increased generalizability compared to previous studies.

Esophageal adenocarcinoma incidence increased by $2.1 \%$ per year, whereas squamous cell carcinoma of the esophagus decreased by $3.6 \%$ per year between 1998 and 2003. However, squamous cell carcinoma rates were similar to, or greater than, adenocarcinoma rates for men and women of all races and ethnicities, except for white or non-Hispanic men. The rate of increase for esophageal adenocarcinoma reported here is smaller than previously observed. Our results highlight the need for continued monitoring of trends at the national level, particularly for esophageal adenocarcinoma, and for determination of factors driving trends. To the extent that changes are due to tobacco and alcohol use and overweight and obesity, findings suggest that public health interventions to address these factors may be warranted.

\section{Acknowledgements}

The authors would like to recognize the contribution of cancer registry staff who collected the data used in this study.

\section{References}

1. American Cancer Society. Cancer facts \& figures 2007. Atlanta: American Cancer Society, 2007.

2. Blot WJ, Devesa SS, Kneller RW, Fraumeni JF, Jr. Rising incidence of adenocarcinoma of the esophagus and gastric cardia. JAMA 1991;265:1287-9.

3. Devesa SS, Blot WJ, Fraumeni JF, Jr. Changing patterns in the incidence of esophageal and gastric carcinoma in the United States. Cancer 1998;83:2049-53.

4. Blot WJ, Devesa SS, Fraumeni JF, Jr. Continuing climb in rates of esophageal adenocarcinoma: an update. JAMA 1993;270:1320.

5. Blot WJ, McLaughlin JK. The changing epidemiology of esophageal cancer. Semin Oncol 1999;26:2-8.

6. El-Serag HB, Mason AC, Petersen N, Key CR. Epidemiological differences between adenocarcinoma of the oesophagus and adenocarcinoma of the gastric cardia in the USA. Gut 2002;50:368-72.
7. Brown LM, Devesa SS. Epidemiologic trends in esophageal and gastric cancer in the United States. Surg Oncol Clin N Am 2002;11:235-56.

8. Younes M, Henson DE, Ertan A, Miller CC. Incidence and survival trends of esophageal carcinoma in the United States: racial and gender differences by histological type. Scand J Gastroenterol 2002;37:135965

9. Kubo A, Corley DA. Marked multi-ethnic variation of esophageal and gastric cardia carcinomas within the United States. Am J Gastroenterol 2004;99:582-8.

10. Wu X, Chen VW, Ruiz B, Andrews P, Su LJ, Correa P. Incidence of esophageal and gastric carcinomas among American Asians/Pacific Islanders, whites, and blacks: subsite and histology differences. Cancer 2006;106:683-92.

11. Wu X, Chen VW, Andrews PA, Ruiz B, Correa P. Incidence of esophageal and gastric cancers among Hispanics, non-Hispanic whites and 
non-Hispanic blacks in the United States: subsite and histology differences. Cancer Causes Control 2007; 18:585-93.

12. Kubo A, Corley DA. Marked regional variation in adenocarcinomas of the esophagus and the gastric cardia in the United States. Cancer 2002;95:2096-102.

13. Daly JM, Karnell LH, Menck HR. National Cancer Data Base report on esophageal carcinoma. Cancer 1996;78:1820-8.

14. Chow WH, Blot WJ, Vaughan TL, Risch HA, Gammon MD, Stanford JL, Dubrow R, Schoenberg JB, Mayne ST, Farrow DC, Ahsan H, West $\mathrm{AB}$, et al. Body mass index and risk of adenocarcinomas of the esophagus and gastric cardia. J Natl Cancer Inst 1998;90:150-5.

15. Farrow DC, Vaughan TL, Sweeney C, Gammon MD, Chow WH, Risch HA, Stanford JL, Hansten PD, Mayne ST, Schoenberg JB, Rotterdam H, Ahsan H, et al. Gastroesophageal reflux disease, use of $\mathrm{H} 2$ receptor antagonists, and risk of esophageal and gastric cancer. Cancer Causes Control 2000;11:231-8.

16. El-Serag HB. Time trends of gastroesophageal reflux disease: a systematic review. Clin Gastroenterol Hepatol 2007;5:17-26.

17. Flegal KM, Carroll MD, Ogden CL, Johnson CL. Prevalence and trends in obesity among US adults, 1999-2000. JAMA 2002;288: 1723-7.

18. Wingo PA, Jamison PM, Hiatt RA, Weir HK, Gargiullo PM, Hutton $\mathrm{M}$, Lee NC, Hall HI. Building the infrastructure for nationwide cancer surveillance and control - a comparison between the National Program of Cancer Registries (NPCR) and the Surveillance. Epidemiology, and End Results (SEER) Program (United States). Cancer Causes Control 2003;14:175-93.

19. Bosetti C, Levi F, Ferlay J, Garavello W, Lucchini F, Bertuccio P, Negri E, La Vecchia C. Trends in oesophageal cancer incidence and mortality in Europe. Int J Cancer 2008;122:1118-29.

20. Hankey BF, Ries LA, Edwards BK. The surveillance, epidemiology, and end results program: a national resource. Cancer Epidemiol Biomarkers Prev 1999:8:1117-21.

21. U.S. Cancer Statistics Working Group. United States Cancer Statistics: 1999-2002 Incidence and Mortality Web-based Report Version. Atlanta: Department of Health and Human Services, Centers for Disease Control and Prevention, and National Cancer Institute, 2005. Available at: www.cdc.gov/cancer/npcr/uscs/. Accessed January 8, 2007.

22. U.S. Cancer Statistics Working Group. United States Cancer Statistics: 1999 Incidence. Atlanta, GA: Department of Health and Human Services, Centers for Disease Control and Prevention and National Cancer Institute, 2002.

23. World Health Organization. International classification of diseases for oncology, 3rd edn. Geneva, Switzerland: World Health Organization, 2000.

24. World Health Organization. International classification of diseases for oncology, 2nd edn. Geneva, Switzerland: World Health Organization, 1990.

25. National Cancer Institute. Conversion programs, ICD-O-2 to 3 and ICD-O-3 to 2 Surveillance, Epidemiology, and End Results (SEER) Program, 2004. Bethesda, MD: National Cancer Institute, 2007.

26. Young JL, Roffers S, Ries L, Fritz A, Hurlbut AA. SEER Summary staging manual 2000. Bethesda, MD: National Cancer Institute, 2000.

27. Shambaugh EM, Weiss MA, Axtell LM. Summary staging guide for the cancer surveillance, epidemiology, and end results reporting (SEER) program. US Department of Health and Human Services: Washington, DC, 1977

28. Howe HL, Jamison M, Havener L, Chen VW, Ries L. Site-specific comparison of summary stage 1977 and summary stage 2000 coding. [Internet] 2007 [cited 2007 January 8]; Available from: http:// www.naaccr.org/index.asp?Col_SectionKey=11\&Col_ContentID=397.

29. Havener L, Hulstrom D. Standards for cancer registries, Volume II: Data standards and data dictionary, 10th ed., Version 11ed. Springfield, IL: North American Association of Central Cancer Registries, 2004.
30. Espey DK, Wu XC, Swan J, Wiggins C, Jim MA, Ward E, Wingo PA, Howe HL, Ries LA, Miller BA, Jemal A, Ahmed F, et al. Annual report to the nation on the status of cancer, 1975-2004, featuring cancer in American Indians and Alaska Natives. Cancer 2007;110:211952.

31. NAACCR Latino Research Work Group. NAACCR Guideline for Enhancing Hispanic/Latino Identification: Revised NAACCR Hispanic/Latino Identification Algorithm [NHIA v2]. Springfield, IL: North American Association of Central Cancer Registries, 2005.

32. Howe HL, Wu X, Ries LA, Cokkinides V, Ahmed F, Jemal A, Miller B, Williams M, Ward E, Wingo PA, Ramirez A, Edwards BK. Annual report to the nation on the status of cancer, 1975-2003, featuring cancer among U.S. Hispanic/Latino populations. Cancer 2006;107:1711-42.

33. Howe HL. Evaluation of NHIA submissions for 1997-2001. Springfield, IL: North American Association of Central Cancer Registries, 2005.

34. Ellison $\mathrm{JH}, \mathrm{Wu} \mathrm{XC}, \mathrm{McLaughlin} \mathrm{CC}$, Lake A, Firth R, Cormier M, Leonfellner S, Carozza S, Roney D, Howe H, Kosary C. Cancer in North America, 1999-2003. vol. 3: NAACCR Combined Incidence. Springfield, IL: North American Association of Central Cancer Registries, 2006.

35. Surveillance Research Program, National Cancer Institute, SEER*Stat software version 6.2.4. Available at: www.seer.cancer.gov/seerstat.

36. Alberts SR, Kelly JJ, Lanier AP, Sacco F. Occurrence of esophageal and gastric cancer in Alaska Natives, 1969-2003. Alaska Med 2006; 48:2-11.

37. Surveillance, Epidemiology, and End Results (SEER) Program (www.seer.cancer.gov) SEER*Stat Database: Incidence-SEER 9 Regs Limited-Use, Nov 2005 Sub (1973-2003)-Linked To County Attributes-Total U.S., 1969-2003 Counties, National Cancer Institute, DCCPS, Surveillance Research Program, Cancer Statistics Branch, released April 2006, based on the November 2005 submission.

38. Gammon MD, Schoenberg JB, Ahsan H, Risch HA, Vaughan TL, Chow WH, Rotterdam H, West AB, Dubrow R, Stanford JL, Mayne ST, Farrow DC, et al. Tobacco, alcohol, and socioeconomic status and adenocarcinomas of the esophagus and gastric cardia. J Natl Cancer Inst 1997;89:1277-84

39. Engel LS, Chow WH, Vaughan TL, Gammon MD, Risch HA, Stanford JL, Schoenberg JB, Mayne ST, Dubrow R, Rotterdam H, West $\mathrm{AB}$, Blaser M, et al. Population attributable risks of esophageal and gastric cancers. J Natl Cancer Inst 2003;95:1404-13.

40. National Center for Health Statistics. Health, United States, 2004 With Chartbook on Trends in the Health of Americansed. Hyattsville, MD: National Center for Health Statistics, 2004.

41. Recommendations regarding interventions to reduce tobacco use and exposure to environmental tobacco smoke. Am J Prev Med 2001;20: $10-15$

42. Katz DL, O'Connell M, Yeh MC, Nawaz H, Njike V, Anderson LM, Cory S, Dietz W. Public health strategies for preventing and controlling overweight and obesity in school and worksite settings: a report on recommendations of the Task Force on Community Preventive Services. MMWR Recomm Rep 2005;54:1-12.

43. Rosenberg HM, Maurer JD, Sorlie PD, Johnson NJ, MacDorman MF, Hoyert DL, Spitler JF, Scott C. Quality of death rates by race and Hispanic origin: a summary of current research, 1999. Vital Health Stat 2 1999:1-13.

44. Clegg LX, Reichman ME, Hankey BF, Miller BA, Lin YD, Johnson NJ, Schwartz SM, Bernstein L, Chen VW, Goodman MT, Gomez SL, Graff JJ, et al. Quality of race, Hispanic ethnicity, and immigrant status in population-based cancer registry data: implications for health disparity studies. Cancer Causes Control 2007;18:177-87.

45. Thoburn KK, German RR, Lewis M, Nichols PJ, Ahmed F, JacksonThompson J. Case completeness and data accuracy in the Centers for Disease Control and Prevention's National Program of Cancer Registries. Cancer 2007;109:1607-16. 